\title{
STUDY OF VARIATIONS IN THE ORIGIN OF AXILLARY NERVE FROM THE POSTERIOR CORD OF BRACHIAL PLEXUS AND ITS CLINICAL IMPORTANCE
}

\section{Suman Tiwari ${ }^{* 1}$, Jyothi N Nayak ${ }^{2}$}

${ }^{{ }_{1}}$ Associate Professor, Department of Anatomy, MVJ Medical College \& Research Hospital, Bangalore, India.

${ }^{2}$ Tutor, Department of Anatomy, MVJ Medical College \& Research Hospital, Bangalore, India.

\section{ABSTRACT}

Background: Axillary nerve, one of the terminal branches of posterior cord of brachial plexus is more prone for iatrogenic injuries. Lack of proper anatomical knowledge and variations of axillary nerve leads to an increased risk of nerve injuries. The present study describes the origin of axillary nerve, its distance of origin from anteromedial aspect of coracoid process, posterolateral aspect of acromion process, and its termination.

Material and Methods: 50 brachial plexuses from 25 adult embalmed human cadavers of both the sexes were studied by dissection method at the Department of Anatomy, MVJ Medical College, Bangalore.

Results: In 41(82\%) specimens, axillary nerve originated from the posterior cord of brachial plexus and in $9(18 \%)$ specimens axillary nerve originated as a common trunk along with thoracodorsal \& lower subscapular or thoracodorsal, upper \& lower subscapular, or only with lower subscapular nerve from the posterior cord of brachial plexus. The mean distance of origin of axillary nerve from the anteromedial aspect of coracoid process and posterolateral aspect of acromion process is $3.67 \mathrm{~cm} \& 6.43 \mathrm{~cm}$ respectively. The axillary nerve terminated into anterior and posterior divisions within quadrangular space in all the specimens.

Conclusion: Knowledge of variations of axillary nerve is of immense significance to clinicians, anaesthetists and orthopaedic surgeons during surgical exploration of neck, axilla and upper arm, fracture of surgical neck of humerus, shoulder dislocation and infraclavicular brachial plexus block.

KEY WORDS: Axillary nerve, Acromion process, Coracoid process, Thoracodorsal, Lower subscapular.

Address for Correspondence: Dr. Suman Tiwari, Associate Professor, Department of Anatomy, MVJ Medical College \& Research Hospital, Hosakote, Bangalore-562114,Karnataka, India.

E-Mail: sumanravi80@gmail.com

\begin{tabular}{|c|c|c|}
\hline \multicolumn{3}{|c|}{ Access this Article online } \\
\hline \multirow{3}{*}{ Quick Response code } & \multicolumn{2}{|c|}{$\begin{array}{l}\text { Web site: International Journal of Anatomy and Research } \\
\qquad \text { ISSN 2321-4287 } \\
\text { www.ijmhr.org/ijar.htm }\end{array}$} \\
\hline & $\begin{array}{l}\text { Received: } 15 \text { June } 2017 \\
\text { Peer Review: } 15 \text { June } 2017\end{array}$ & $\begin{array}{l}\text { Accepted: } 03 \text { Aug } 2017 \\
\text { Published (O): } 31 \text { Aug } 2017\end{array}$ \\
\hline & Revised: None & Published (P): 31 Aug 2017 \\
\hline
\end{tabular}

\section{INTRODUCTION}

The brachial plexus which is formed by platuing of the ventral rami of $\mathrm{C} 5, \mathrm{C} 6, \mathrm{C} 7, \mathrm{C} 8$ and $\mathrm{T} 1$ supplies motor, sensory and sympathetic fibres to the upper limb. It extends from the neck downwards and laterally over the first rib, posterior to the clavicle and enters the axilla. The brachial plexus consists of three cords-lateral, medial and posterior which branch inferior to the clavicle. The posterior cord runs posterior to the second part of the axillary artery and gives off the following branches - upper subscapular nerve, thoracodorsal nerve, lower subscapular nerve, axillary nerve and then continues as a large terminal branch, the radial nerve. The axillary nerve leaves the posterior wall of axilla 
along with posterior circumflex humeral vessels and enters the quadrangular space. The trunk of axillary nerve while passing through the quadrangular space gives a first branch to shoulder joint, there after it divides into anterior and posterior branches [1].

Axillary nerve is one of the most important nerves which is prone for iatrogenic injuries. The axillary nerve is most commonly injured (6\% of all the brachial plexus injuries) during numerous orthopaedic surgeries like shoulder arthroscopy, thermal shrinkage of the shoulder capsule (excessive temperature) and plate fixation (retraction of deltoid muscle) of the proximal humerus [2]. Anatomical variations of axillary nerve are one of the causes of these iatrogenic injuries. Variations of axillary nerve are important during fracture of surgical neck of humerus and in quadrangular space syndrome. Lack of proper anatomical knowledge also leads to increased risk of nerve injury during intramuscular injections in the deltoid [3]. The present study is undertaken to know the incidence of variations in the origin of axillary nerve from the posterior cord of brachial plexus and its Clinical Importance.

\section{MATERIALS AND METHODS}

Fifty brachial plexuses of 25 adult embalmed human cadavers from south Indian population were studied irrespective of their sex. The specimens were obtained from the Department of Anatomy, MVJ Medical College, Bangalore. The gross dissection was done following the guidelines of Cunningham's manual. The loose connective tissue, fat $\&$ lymph nodes from the axilla were removed to expose its contents. The axillary artery, vein and large nerves surrounding them were exposed. The smaller tributaries of the vein were removed to get a clear view of the nerves. The radial nerve was identified behind the artery. The axillary nerve passing backwards with posterior circumflex humeral artery was traced at the lower border of subscapularis. The anterior surface of subscapularis was exposed. The upper subscapular, lower subscapular \& thoracodorsal nerves were followed to their origin from the posterior cord of brachial plexus. The origin of axillary nerve and its termination into anterior \& posterior divisions was observed in all the specimens. The distance of origin of axillary nerve from the anteromedial aspect of tip of coracoid process \& posterolateral aspect of acromion process was measured using sliding calipers. The data obtained was entered in Microsoft excel and analyzed using SPSS $16^{\text {th }}$ version. Mean and standard deviation was calculated. The results obtained were compared with that of previous studies.

\section{RESULTS}

Fig. 1: Common trunk of origin of axillary, thoracodorsal \& lower subscapular nerve.

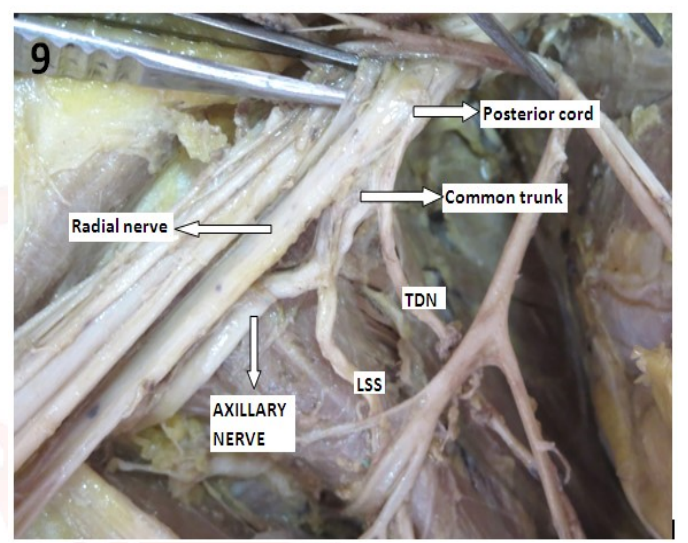

Fig. 2: Common trunk of origin of upper subscapular, thoracodorsal, lower subscapular \& axillary nerve.

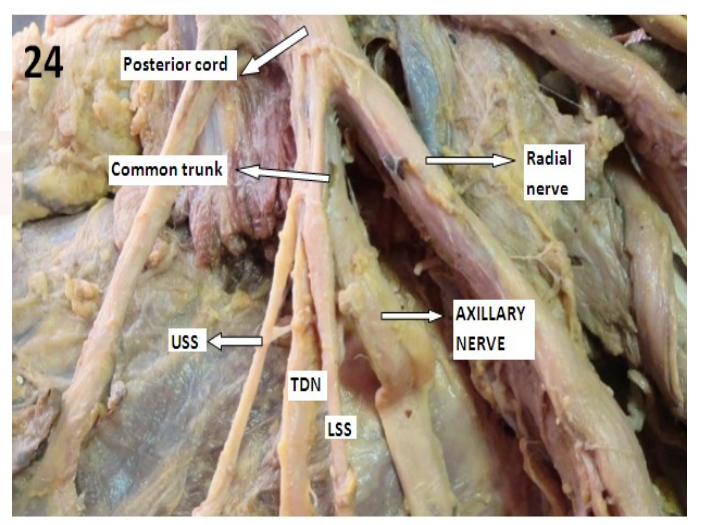

Fig. 3: Common trunk for lower subscapular \& axillary nerve.

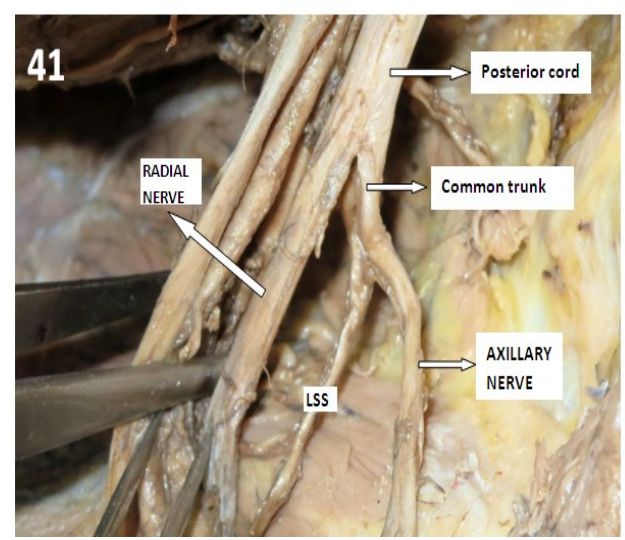

TDN-Thoracodorsal nerve, LSS- Lower subscapular nerve, USS- Upper subscapular nerve 
Table 1: Showing distance of origin of axillary nerve from the anteromedial aspect of tip of coracoid process and posterolateral aspect of acromion process.

\begin{tabular}{|l|c|c|}
\hline & \multicolumn{2}{|c|}{ Distance of origin of axillary nerve } \\
\cline { 2 - 3 } & $\begin{array}{c}\text { Anteromedial aspect of } \\
\text { tip of coracoid process } \\
(\mathrm{cm})\end{array}$ & $\begin{array}{c}\text { Posterolateral aspect of } \\
\text { acromion process (cm) }\end{array}$ \\
\hline MIN- MAX & $2.16-6.10$ & $5.14-8.46$ \\
\hline MEAN \pm SD & $3.67 \pm 0.98$ & $6.43 \pm 1.09$ \\
\hline
\end{tabular}

Table 2: Showing the percentage of origin of axillary nerve as a common trunk from posterior cord by different authors.

\begin{tabular}{|c|c|c|c|}
\hline Author & $\begin{array}{c}\text { Number of } \\
\text { specimens }\end{array}$ & $\begin{array}{c}\text { Origin from } \\
\text { posterior cord }\end{array}$ & $\begin{array}{c}\text { Origin as a common } \\
\text { trunk from posterior } \\
\text { cord }\end{array}$ \\
\hline Darji A et al. 2013 [4] & 100 & $99 \%$ & $1 \%$ \\
\hline Bhosale SM et al 2014 [5] & 40 & $87.50 \%$ & $12.50 \%$ \\
\hline Rastogi R et al 2012 [6] & 74 & $77.10 \%$ & $22.90 \%$ \\
\hline Gaur S et al. 2012 [7] & 50 & $92 \%$ & $8 \%$ \\
\hline Chaudhary P et al. 2011 [8] & 60 & $96.67 \%$ & $3.33 \%$ \\
\hline Present study & 50 & $82 \%$ & $18 \%$ \\
\hline
\end{tabular}

Table 3: Showing distance of origin of axillary nerve from anteromedial aspect of tip of coracoid process and posterolateral aspect of acromion process by different authors.

\begin{tabular}{|c|c|c|c|}
\hline Author & $\begin{array}{c}\text { Number of } \\
\text { specimens }\end{array}$ & $\begin{array}{c}\text { Distance from } \\
\text { coracoid process } \\
(\mathrm{cm})\end{array}$ & $\begin{array}{c}\text { Distance from } \\
\text { acromion process } \\
(\mathrm{cm})\end{array}$ \\
\hline Gurushantappa PK et al 2015 [3] & 50 & 3.56 & 7.46 \\
\hline Tubbs RS et al. 2011 [9] & 30 & 4 & - \\
\hline Uz A et all 2007 [10] & 75 & - & 7.8 \\
\hline Burkhead WZ et al 1992 [11] & 56 & - & 5 \\
\hline Present study & 50 & 3.67 & 6.43 \\
\hline
\end{tabular}

Out of the 50 specimens studied, axillary nerve was originating from the posterior cord of brachial plexus in $41(82 \%)$ specimens. The remaining $9(18 \%)$ specimens showed a common trunk of origin of axillary nerve from posterior cord of brachial plexus. It was observed that out of the $9(18 \%)$ specimens, a common trunk for axillary, thoracodorsal \& lower subscapular (Fig 1) was found in $3(6 \%)$ specimens, common trunk for upper \& lower subscapular, thoracodorsal \& axillary nerve( Fig 2) in 2(4\%) specimens and a common trunk for lower subscapular $\&$ axillary nerve ( Fig 3 ) in $4(8 \%)$ specimens. The mean distance of origin of axillary nerve from the anteromedial aspect of tip of coracoid process and posterolateral aspect of acromion process is $3.67 \mathrm{~cm} \& 6.43 \mathrm{~cm}$ respectively. (Table 1 ) The axillary nerve terminated into anterior and posterior divisions within quadrangular space in all the specimens.

\section{DISCUSSION}

The incidence of origin of axillary nerve as a common trunk from the posterior cord of brachial plexus varies from $1 \%-22.9 \%$ in various studies. [4-8] and is summarized in Table 2 . The highest incidence was reported by Rastogi ${ }^{6}$ $(22.9 \%)$ and the lowest by $\operatorname{Darji}^{4}(1 \%)$. In the present study, its incidence is $18 \%$ which is within the range.

The mean distance of origin of axillary nerve from the anteromedial aspect of tip of coracoid process and posterolateral aspect of acromion process of different studies [3,9-11] is compared with present study and is summarized in Tab 3.

Ozgur Cetik et al [12], studied the distance of origin of axillary nerve from the acromion and its relation to arm length, and identified a safe area above the axillary nerve which is quadrangular in shape, with the length of the lateral edges being dependent on the individual's arm length. The axillary nerve was not found to lie at a constant distance from the acromion at every point along its course.

The embryological basis for the origin of axillary nerve as a common trunk from the posterior cord of brachial plexus is as follows.

Position and width of a limb bud determine its innervations; limb bud is supplied by nerves of region where it is implanted. Segregation of the developing structure within the limb directs growing nerve fibres (axons) and determines their grouping into bundles leading to formation of roots and trunks. As the expression of chemoattractants and chemorepulsants regulates the growing nerve fibres (axons) in a highly coordinated site-specific fashion, any alterations in signalling between the mesenchymal cells and neuronal growth cones can lead to significant variations [6]

The variations occur at the junction or separation of individual parts and may be due to an unusual formation during the development of the trunks, divisions, or cords [8].

Muthoka [13] studied 75 brachial plexus in Kenyan population and found a wide range of variations in the order of branching of posterior cord. Some of his variations included a common trunk for axillary, thoracodorsal \& lower 
subscapular from posterior cord and a common trunk for upper, middle, lower subscapular \& axillary nerve. Axillary nerve has also been used as a landmark for identifying the lower subscapular nerve during glenohumeral joint surgery.

Gurushantappa [3] in his study of 50 specimens found that the axillary nerve divided into anterior and posterior branches in Quadrangular space in $88 \%$ cases \& within deltoid muscle in $12 \%$. In the present study, in all the specimens, the axillary nerve terminated into anterior and posterior divisions within quadrangular space.

Descriptions of peripheral nerve variations are useful in clinical and surgical practice, since an anatomical variation can be the cause of nerve palsy syndromes and vascular problems. They are of particular importance during diagnosis of injuries of the plexus, neck dissections, infraclavicular block procedures and surgical approaches to axillary region tumours where these unusual distributions are prone to damage. Further, identification of specific nerves originating from posterior cord of brachial plexus is necessary during neurotisation processes.

Clinically, trauma of the posterior wall of the axillary region could present with a wide range of degrees of muscle impairment For instance, lesions involving common trunk for axillary nerves and thoracodorsal nerve may produce more extensive functional lesions including lattisimus dorsi, deltoid and teres minor muscles $[7,13]$.

The shoulder joint dislocation and rotator cuff tear causes nerve injury which is called "unhappy triad" of the shoulder joint. The axillary nerve is vulnerable to damage during acute trauma to the shoulder or by chronic repeated trauma like in 'quadrilateral space syndrome' (entrapment of axillary nerve). Lack of proper anatomical knowledge of nerve also leads to an increased risk of nerve injury during intramuscular injections in deltoid, intra-articular and intra-bursal steroid injections [3, 14].

\section{CONCLUSION}

Variations in the origin of axillary nerve from the posterior cord of brachial plexus is a common anomaly found in $18 \%$ of specimens. Knowledge of these variations is important to surgeons during surgical exploration of axilla for axillary tumours, neck during neck dissections, surgical treatment of tumours of nerve sheath such as schwannoma \& neurofibroma, shoulder dislocation \& rotator cuff tear. Furthermore, knowledge of variant anatomy of axillary nerve is of greatest importance to anaesthetists during administration of anaesthetic blocks and clinicians for interpreting effects of nerve injuries \& nerve compressions of upper limb.

\section{ACKNOWLEDGEMENT}

I sincerely thank our principal of MVJ Medical College \& Research Hospital, Bangalore, for giving me permission to carry out the research work.

\section{Conflicts of Interests: None}

\section{REFERENCES}

[1]. Standring S. Gray's anatomy. Pectoral girdle, Shoulder region, Axilla. The Anatomical basis of clinical practice. $40^{\text {th }}$ Ed., London: Elsevier Churchill Livingstone; 2008:821-22.

[2]. Marios Loukas, Joanna Grabska, Shane Tubbs, Nihal Apaydin, Robert Jordan. Mapping the axillary nerve within the deltoid muscle. Surgical and Radiologic Anatomy. 2009;31(3):43-47.

[3]. Gurushantappa PK, Kuppasad S. Anatomy of Axillary Nerve and Its Clinical Importance: A Cadaveric Study. Journal of Clinical and Diagnostic Research. 2015;9(3):AC13-AC17.

[4]. Darji A, Chauhan H, Khatri H, Aterkar S, Pensi CA. Variations in Branching Pattern of Brachial Plexus: A Cadaveric study. Int Journal of Biomedical and Advance Research. 2013;4(3):174-178.

[5]. Bhosale SM, Mallashetty NS. Study of variations in the origin and distance of origin of axillary nerve of the posterior cord of brachial plexus. Int J Cur Res Rev. 2014;6(15):41-44.

[6]. Rastogi R, Budhiraja V, Bansal K. Posterior Cord of Brachial Plexus and Its Branches: Anatomical Variations and Clinical Implication. Hindwai Publishing Corporation ISRN Anatomy. 2012;2013:1-3.

[7]. Gaur S, Katariya SK, Vaishnani H, Wani IN, Bondre $\mathrm{KV}$ et al. A cadaveric study of variation of posterior cord of brachial plexus. Int J Biol Med Res. 2012;3(3):2214-2217.

[8]. Chaudhary P, Singla R, Kalsey G, Arora K. Branching pattern of the posterior cord of brachial plexus: $A$ cadaveric study. Journal of Clinical and Diagnostic Research. 2011;5(4):787-790.

[9]. Tubbs RS, Oakes PAC, Blount JP, Salter G, et al. Surgical landmarks for the proximal portion of the axillary nerve. Journal of Neurosurgery. 2001;95(6):998-1000.

[10]. Uz A, Apaydin N, Rozkut M, Fihan A. The anatomic branch pattern of the axillary nerve. Journal of Shoulder \& Elbow Surgery. 2007;16(2):240-44. 
[11]. Burkhead WZ, Scheinberg RR, Box G. Surgical anatomy of the axillary nerve. J Shoulder Elbow Surg. 1992;1:31-36.

[12]. Cetik O, Uslu M, Acar HI, Comert A, Tekdemir I et al. Is there a safe area for the axillary nerve in the deltoid muscle? Journal of Bone and Joint Surgery. 2006; 88-A.

[13]. Muthoka JM, Sinkeet SR, Shahbal SH, Matakwa LC, Ogeng'O JA. Variations in branching of the posterior cord of brachial plexus in a Kenyan population. Journal of Brachial Plexus and Peripheral Nerve Injury. 2011;6:1
[14]. Apaydin N, Tubbs RS, Loukas M, Dupare F. Review of the surgical Anatomy of the axillary nerve and the anatomic basis of its iatrogenic and traumatic injury. Surg \& Radiol Anat. 2010; 32(3): 193-201.

How to cite this article:

Suman Tiwari, Jyothi N Nayak. STUDY OF VARIATIONS IN THE ORIGIN OF AXILLARY NERVE FROM THE POSTERIOR CORD OF BRACHIAL PLEXUS AND ITS CLINICAL IMPORTANCE. Int J Anat Res 2017;5(3.2):4242-4246. DOI: 10.16965/ijar.2017.296 